\title{
A COMPREENSÃO DOS ESTUDANTES SOBRE O PAPEL DA IMAGINAÇÃO NA PRODUÇÃO DAS CIÊNCIAS
}

\author{
Helder de Figueirêdo e Paula \\ Colégio Técnico - UFMG \\ CECIMIG-FAE - UFMG \\ Antônio Tarciso Borges \\ Colégio Técnico - UFMG \\ Programa de PG em Educação - UFMG \\ Belo Horizonte - MG
}

\section{Resumo}

O uso da imaginação e a produção de modelos é uma das marcas distintivas da atividade científica. Ainda assim, na educação básica, as ciências são normalmente caracterizadas como sendo uma mera coleção de fatos obtidos mediante a observação rigorosa realizada por meio de "métodos objetivos" de investigação. Essa visão de ciência empirista-indutivista deixa pouco espaço para compreendermos o caráter provisório do conhecimento e o papel da imaginação na produção das ciências. Neste trabalho relatamos alguns resultados de uma pesquisa destinada a promover imagens mais sofisticadas da atividade cientifica entre estudantes de uma turma de Ensino Fundamental, acompanhados enquanto cursavam a $7^{a}$ e a $8^{a}$ séries. Nesse periodo, os estudantes tiveram a oportunidade de lidar com um professor de ciencias especialmente comprometido com o objetivo de sofisticar o conhecimento epistemológico de seus estudantes e motivado para participar de nossa pesquisa. Os resultados indicam que os estudantes reconhecem a importância e a legitimidade do uso da imaginação na produção

\footnotetext{
' The students' understanding on the imaginary role in Science production

* Recebido: dezembro de 2007. Aceito: abril de 2008
} 
das ciências. Eles parecem ter sido paulatinamente convencidos durante os dois últimos anos do Ensino Fundamental de que para explicar é preciso ir além do que se pode efetivamente observar. Os estudantes adquiriram a convicção de que não se avalia a qualidade de uma explicação ou teoria levando-se em conta se ela contém mais ou menos elementos extraídos da imaginação. O critério para realizar tal avaliação desloca-se para o julgamento do acordo entre teorias, explicações, observações e evidências.

Palavras-Chave: Ensino de ciências; natureza das ciências; conhecimento epistemológico dos estudantes.

\begin{abstract}
The use of imagination and production of models are distinctive traits of scientific activity. Despite of that, basic school Science Education characterises Science as a mere collection of facts obtained from neutral and rigorous observations of things and phenomena combined with 'objective scientific methods' of investigation. This empiric-inductive view of Science lets little margin to understanding the tentative character of scientific knowledge and the crucial creative and imaginary human role plays in its production. In this work, we report part of the results of a research aimed at promoting the development of more sophisticated images of Science and of scientific knowledge among Middle School students during the last two grades, i.e., grades 7 and 8. Along that time those students were taught by a young and enthusiastic Science teacher committed to the idea of creating opportunities for promoting reflections about some aspects of the nature of scientific activity. Results indicate that the students came to acknowledge the importance and legitimacy of using imagination in scientific knowledge production. They seemed to have been gradually convinced through that two-year period about the idea that in order to produce good explanations one must go beyond that immediate tangible and observable reality. Students appeared convinced that explanation or theory evaluation do not depend on if it contains more or less elements of imagination. It is
\end{abstract}


a matter of judging the quality of the agreement between the explanation and the available evidences.

Keywords: Science Education; nature of Science; students' epistemological knowledge.

\section{Introdução}

Uma das metas centrais fixadas por várias propostas curriculares recentes (AAAS, 1989; NRC, 1996; MEC, 1998; MILLAR; OSBORNE, 1998) é a de que estudantes sejam ajudados a desenvolver entendimentos mais informados sobre o que é a ciência e sobre como o conhecimento científico é produzido e validado. Além de aprender conceitos, modelos e teorias produzidos historicamente pelas ciências, esses documentos defendem a necessidade de que a educação escolar promova um conhecimento mais elaborado sobre as ciências. Conquanto possa ser relativamente fácil encontrar consenso sobre a importância de incorporar este ponto de vista na elaboração de uma educação em ciências para todos, há muito ainda que se discutir e que se compreender sobre como isso pode ser feito (LEACH; RYDER, 2003).

As razões que justificam o ensino de tópicos aspectos da natureza e do estatuto das ciências na educação básica são variadas. Lederman (1999) relaciona esse ensino com a possibilidade de aumentar o interesse dos estudantes nos assuntos das ciências. Driver et al. (1996) afirmam que uma maior compreensão dos estudantes acerca da natureza das ciências pode facilitar sua tomada de decisão em questões ligadas à tecnologia e ciência, pois, afinal, a ciência é um empreendimento cultural que tem forte impacto sobre a vida das sociedades. Documentos concebidos no contexto da reforma da educação em ciências nos Estados Unidos (AAAS, 1989) justificam o ensino de aspectos da natureza das ciências pelo seu valor intrínseco, isto é, como parte da alfabetização científica.

A literatura no campo da educação em ciências sugere um amplo acordo sobre a importância de considerar alguns aspectos da natureza da ciência e do empreendimento científico como conhecimentos relevantes o bastante para serem inclusos nos currículos de ciências da educação básica, mas há poucos indicadores de sucesso em iniciativas voltadas para o alcance dessa meta. O que existem são evidências de pesquisa com pequenos grupos de estudantes. Tais pesquisas sugerem que as crenças e concepções dos estudantes sobre os processos de produção e validação do conhecimento científico afetam suas tentativas de aprender ciências 
(DUSCHL, 1990; SONGER; LINN, 1991; SMITH et al, 2000; LEACH; LEWS, 2002).

Segundo Akerson, Abd-El-Khalick e Lederman (2000), a meta de ajudar os estudantes a desenvolver imagens mais sofisticadas sobre a natureza das ciências tem sido compartilhada entre educadores, cientistas e organizadores de currículo há, pelo menos, oito décadas. Durante a maior parte do tempo existiram desacordos sobre que aspectos da natureza da ciência deveriam ser ensinados dentro das atividades de ciências. Nas duas últimas décadas, em vista da ênfase conferida a esta meta pelo movimento de reforma da educação em ciências nos Estados Unidos e Reino Unido, estabeleceu-se um conjunto de idéias fundamentais que caracterizam hoje o tópico. Assim, quando mencionamos aprender sobre a natureza das ciências e do conhecimento científico, estamos nos referindo a um conjunto limitado de idéias.

Desse conjunto destacamos a idéia de que a ciência é um empreendimento social, parte fundamental da cultura humana e que está sujeita a mudanças e revisões. A produção de conhecimento científico envolve a comunicação e o debate entre cientistas em encontros e através de publicações. A qualidade dos argumentos apresentados é fundamental para que um cientista ou um grupo defenda seus pontos de vista. Uma teoria ou explicação ganha aceitação, é revista ou abandonada através de um processo complexo de negociação social entre grupos de cientistas. Nesses processos, promove-se um debate sobre a organização, a lógica e a coerência da teoria, mediante uma comparação entre suas previsões e os fatos conhecidos, bem como uma avaliação de seu potencial como instrumento de explicação de fenômenos cuja compreensão é julgada importante. Esta idéia está em contraste com a concepção usual de professores e estudantes de que o conhecimento científico é verdadeiro e imutável, sendo descoberto por cientistas brilhantes que, em geral, trabalham solitariamente em seus laboratórios. Às vezes, professores e estudantes até admitem que teorias possam ser mudadas, desde que essa mudança implique na substituição de idéias equivocadas por idéias corretas. Uma visão mais sofisticada das ciências concebe o processo de substituição de teorias aceitas por novas teorias como o resultado de um processo social de negociação para alcançar consenso sobre qual das teorias competidoras melhor explica os fatos e qual delas supostamente exibe maior potencial em termos de pesquisas futuras. Em geral, as teorias que ganham maior aceitação são aquelas que conseguem explicar fatos e observações que as antigas não conseguiam e que, às vezes, sequer existiam na época em que elas foram originalmente formuladas. 
Uma segunda idéia associada a essa visão mais sofisticada das ciências é a de que o conhecimento científico não é absolutamente provado e objetivo, como os estudantes acreditam, pois ele não corresponde à realidade "tal como ela é". Nós não temos acesso privilegiado ao mundo físico. Os conceitos que a ciência utiliza são criações humanas para formular explicações e modelos de que é feito o mundo e de como ele se comporta. Nossas observações e dados sobre fenômenos que observamos são dependentes do que já sabemos e de nossas interpretações e inferências sobre o significado desses dados e observações. Por exemplo, podemos descrever, prever e explicar o comportamento de vários sistemas de diferentes áreas do conhecimento com base no conceito de energia, associado às idéias de sua conservação e transformação. Ainda assim, energia continua sendo um conceito abstrato e diz respeito a algo intangível. Em outras palavras, nem mesmo sabemos o que energia é "exatamente". Não observamos "energia", mas podemos inferir a conservação ou transformação de energia a partir de variáveis que podemos medir.

A terceira idéia que acreditamos ser importante que os estudantes da educação básica compreendam é a de que o conhecimento científico tem uma base empírica, mas ao mesmo tempo, é dependente da imaginação e da criatividade humana (AAAS, 1989; NRC, 1996; NRC, 1996; MILLAR e OSBORNE, 1998). A qualidade dos modelos e teorias que formulamos está associada à nossa capacidade de compreender o comportamento dos vários fenômenos que observamos se as condições nas quais eles se realizam forem alteradas. Por meio da imaginação e da criatividade somos capazes de conceber mundos possíveis e fenômenos plausíveis ainda que, em um dado momento, inexistentes. Assim, em última instância, os modelos e teorias científicas nos auxiliam a alterar o real e transformam a ciência em realização, isto é, em uma ação a partir da qual podemos transformar o real.

Esse é o caso, por exemplo, das ondas eletromagnéticas que foram inicialmente introduzidas em um mundo de possibilidades, pelas equações de Maxwell, para depois transformarem-se no fenômeno "real" nos aparatos construídos por Hertz. Algum tempo depois de surgirem como algo possível e serem transformadas em um "fenômeno real", tais ondas modificaram radicalmente a cultura e a economia, contribuindo para o surgimento da era da informação e da telecomunicação na qual estamos hoje inseridos.

A ampla divulgação das três idéias acima descritas no seio da comunidade de pesquisa em educação em ciências e sua presença no interior de documentos de orientação curricular não garante sua difusão entre professores e alunos da educação básica. Diversas pesquisas têm demonstrado que a grande maioria dos alunos e dos professores de ciências naturais apresenta concepções de senso comum sobre 
vários aspectos da atividade científica (ABD-EL_KHALICK; LEDERMAN, 2000; RUBBA; ANDERSON, 1978). Os cursos de ciências usualmente conferem pouca importância ao conhecimento sobre a ciência, preferindo enfatizar a aprendizagem de leis, conceitos e fatos produzidos pelas ciências (HODSON, 1988; LEMKE, 2002).

Os currículos reais - realizados nas salas de aula - caracterizam as ciências de modo implícito. Como consequiência disso, os estudantes, mesmo dos cursos de graduação, e os professores, em geral, entendem o conhecimento científico como algo verdadeiro, imutável e provado, fruto de descobertas realizadas por gênios quase supra-humanos. É essa caracterização do conhecimento que os livros didáticos e professores tradicionalmente exibem. Aos estudantes, resta se sujeitar a um ensino dogmático e aprender a "respeitar" a autoridade dos cientistas, livros, autores e professores. Resta a eles recorrer à memorização dos enunciados e "fatos científicos", além de exercitar a passividade para aprender a reproduzir afirmações de conhecimento e a responder às questões de testes, sem "brigar" com elas, ou seja, sem aprender a pensar sobre as implicações do conhecimento científico.

No presente artigo, apresentamos um referencial para orientar as ações de professores e pesquisadores em seus esforços para introduzir tópicos destinados a promover reflexões sobre natureza das ciências na educação básica. Trata-se de tópicos sobre os quais há razoável consenso na bibliografia da área de educação em ciências (OSBORNE; COLLINS; RATCLIFFE; MILLAR; DUSCHL, 2003). Relatamos, ainda, parte dos resultados de uma pesquisa destinada a investigar mudanças a serem instituídas na educação escolar para que ela se torne um instrumento para a compreensão da atividade científica enquanto um empreendimento cultural. Aqui discutimos em que medida os estudantes compreendem o papel da imaginação dos cientistas na criação de teorias científicas. Na pesquisa que realizamos, acompanhou-se uma turma de adolescentes em parte do período em que eles cursavam os dois últimos anos do Ensino Fundamental junto a um professor comprometido com o avanço do conhecimento epistemológico dos estudantes.

\section{Aspectos da natureza das ciências no currículo}

Leach e Lews (2002) citam diversos estudos que indicam algumas características comuns ao conhecimento epistemológico ingênuo dos estudantes que podem interferir decisivamente em sua capacidade de compreender as idéias das ciências: 
Muitos estudantes tendem a atribuir um peso excessivo aos dados empíricos quando analisam o modo como as disputas entre teorias científicas são resolvidas ou o modo como os pontos de vista das ciências são justificados. O conhecimento científico, expresso nas leis, é visto como conhecimento verdadeiro e absolutamente provado sobre o mundo. Teorias e hipóteses, ao contrário, são idéias que ainda precisam ser demonstradas através de observações e dados empíricos. Quando há dados e observações suficientes para "provar" uma teoria, ela se transforma em uma lei.

Essas concepções sobre a ciência estão em desacordo com a perspectiva de filósofos e cientistas de que a "aprovação" de uma teoria nesse sentido absoluto é uma impossibilidade na ciência, uma vez que temos uma percepção limitada do universo, e de que leis e teorias científicas têm bases em tipos distintos de evidências. Leis e teorias representam conhecimentos diferentes e têm papéis distintos na ciência. As leis expressam regularidades que dizem o que acontece em certas condições e têm base empírica. As teorias são baseadas em inferências que produzem explicações de por que certos fenômenos acontecem.

Além disso, ao contrário do que supõe o senso comum, as teorias têm um status epistemológico superior às leis. Afinal, são as teorias que nos permitem especular melhor sobre o que é possível, impossível ou logicamente necessário. As leis nos dão acesso a previsões empíricas. As teorias nos revelam possíveis razões que justificam tais previsões.

Os estudantes parecem assumir uma simples correspondência entre entidades que pertencem a uma explicação científica e objetos ou eventos no mundo material. Podemos dizer que eles são realistas ingênuos, o que foi notado durante o período inicial de acompanhamento da turma. Isso os impede de reconhecer que, em muitos casos, as explicações e proposições elaboradas nas ciências são povoadas por entidades teóricas e baseadas em modelos e situações idealizadas, fruto da imaginação e criatividade dos cientistas.

Mas, como superar esse quadro? Que mudanças devem ser instituídas no ensino de ciências para que ele venha a se tornar um apoio àqueles eventualmente interessados na compreensão da atividade científica? Esse é o problema que gerou a pesquisa relatada neste trabalho.

O primeiro passo para compreender melhor a complexidade e as implicações desse problema consiste em reconhecer que a ciência escolar constitui um corpo de conhecimento que busca representar a atividade científica, em alguma medida, mas não se confunde com ela (ASTOLFI; DEVELAY, 1989; CHEVELLARD, 1991). O segundo passo implica em compreender que a atividade científica 
constitui um empreendimento cultural e social altamente complexo e pode ser caracterizado, tanto por seus múltiplos produtos materiais e intelectuais, quanto pela diversidade de seus processos.

Por essa razão, o problema que a compreensão da atividade científica na educação básica nos coloca diz respeito às escolhas didáticas, ideológicas e epistemológicas mediante as quais as ciências são representadas. Tais escolhas podem, ou não, contribuir para que a ciência escolar se torne um instrumento para promover a compreensão da atividade científica.

O ensino de ciências naturais no Brasil tem estado centrado no compromisso de promover o acesso dos estudantes a um determinado conjunto de conceitos, modelos e teorias geradas no interior das ciências. Esse foco pode ser caracterizado como um foco no ensino de produtos do conhecimento científico. Sem desmerecer a importância dessa dimensão do ensino, acreditamos que o foco exclusivo sobre ela impõe uma grave restrição às contribuições da educação em ciências $^{1}$.

Por enfatizar a aprendizagem dos conteúdos presentes nos livros, que normalmente se restringem à "ciência pronta", os professores não promovem oportunidades para que os estudantes discutam como o conhecimento científico é produzido e validado, e não contribuem para que os seus estudantes desenvolvam algum entendimento sobre as táticas e estratégias utilizadas na concepção, avaliação e validação do conhecimento.

Millar (1996) discute quais papéis a disciplina ciências cumpriria num currículo voltado para a educação de todos os cidadãos e nos ajuda a vislumbrar outras dimensões do ensino para além dos produtos do conhecimento científico. Ele destaca e caracteriza três aspectos de uma compreensão de ciências que devem ser simultaneamente priorizadas pelos currículos:

$1^{\circ}$ - a compreensão do conteúdo científico (ou conhecimento científico substantivo);

$2^{\circ}$ - a compreensão dos métodos de investigação usados em ciência;

$3^{\circ}$ - a compreensão da ciência como um empreendimento social.

Outra maneira de nos referirmos aos aspectos mencionados por Millar é mediante a tríade "aprender ciências", "aprender a fazer ciências" e "aprender sobre ciências" (HODSON, 1988). A correspondência entre essas três dimensões

\footnotetext{
${ }^{1}$ Para simplificar a linguagem iremos nos referir às ciências naturais nesse trabalho simplesmente pelo termo ciências. Obviamente, não entendemos que as ciências se resumem às ciências naturais.
} 
do ensino-aprendizagem e os três aspectos destacados por Millar não é exata. Aprender sobre ciências envolve a compreensão tanto dos métodos de investigação, quanto das dinâmicas sociais que caracterizam as ciências como um empreendimento cultural e social. Por outro lado, aprender a fazer ciências transcende o nível da compreensão, pois envolve aspectos de natureza tácita.

Promover o "aprender ciências" implica em viabilizar o acesso dos estudantes a leis, conceitos, modelos e teorias fundamentais, historicamente desenvolvidos pelas ciências naturais. Esse desafio está intrinsecamente ligado à realização dos dois outros tipos de aprendizagem mencionados, na medida em que não há como sofisticar a compreensão dos estudantes "sobre as ciências" sem contribuir para que eles compreendam o conteúdo das idéias das ciências. Do mesmo modo, não há como "aprender a fazer ciências" sem utilizar idéias e conceitos das ciências.

Aprender ciências e aprender sobre ciências são dois conteúdos indissociáveis e complementares, embora sejam irredutíveis um ao outro. Assim, quando dizemos que a educação básica tradicionalmente focaliza seus esforços apenas no ensino de produtos do conhecimento científico, não estamos querendo dizer que ela não promove uma aprendizagem "sobre as ciências" e uma determinada compreensão do que seja "fazer ciências". Contudo, ao focalizar apenas uma dimensão da educação em ciências, a escola desloca as outras dimensões para uma espécie de "currículo oculto", que não é objeto do planejamento pedagógico. As referências explícitas às características da atividade científica tornam-se escassas ou desarticuladas, e costumam veicular uma visão pobre, distorcida e mistificadora das ciências. Desse modo, o ensino focado apenas nos produtos das ciências inibe diversas contribuições potenciais da educação escolar para a formação de sujeitos críticos e capazes de exercer alguma autonomia intelectual.

Acreditamos que o grande desafio envolvido na articulação do ensino dos produtos do conhecimento científico com o "ensinar a fazer" e o "ensinar sobre as ciências" consiste em: $1^{\circ}$ - evitar reducionismos e mistificações dos processos da ciência; $2^{\circ}$ - promover uma compreensão mais rica e sofisticada da natureza das ciências; $3^{\circ}$ - permitir o desenvolvimento de práticas de produção de conhecimento científico, que são potencialmente importantes para a vida em sociedade; $4^{\circ}$ - viabilizar o acesso dos estudantes a conceitos, modelos e teorias fundamentais, historicamente desenvolvidos pelas ciências naturais.

Para enfrentar esse desafio é necessário desenvolver ou delimitar, de forma consistente, um conhecimento sobre a ciência que possa ser incorporado ao 
currículo e às práticas pedagógicas da educação básica ${ }^{2}$. Há divergências nas propostas curriculares recentes acerca de quais aspectos desse conhecimento sobre a ciência o currículo deveria priorizar e de como fazê-lo, isto é, tratar este conhecimento como novos conteúdos do currículo ou abordá-los no contexto do ensino de conteúdos usuais (AAAS, 1989; NRC, 1996; MEC, 1998; MILLAR; OSBORNE, 1998).

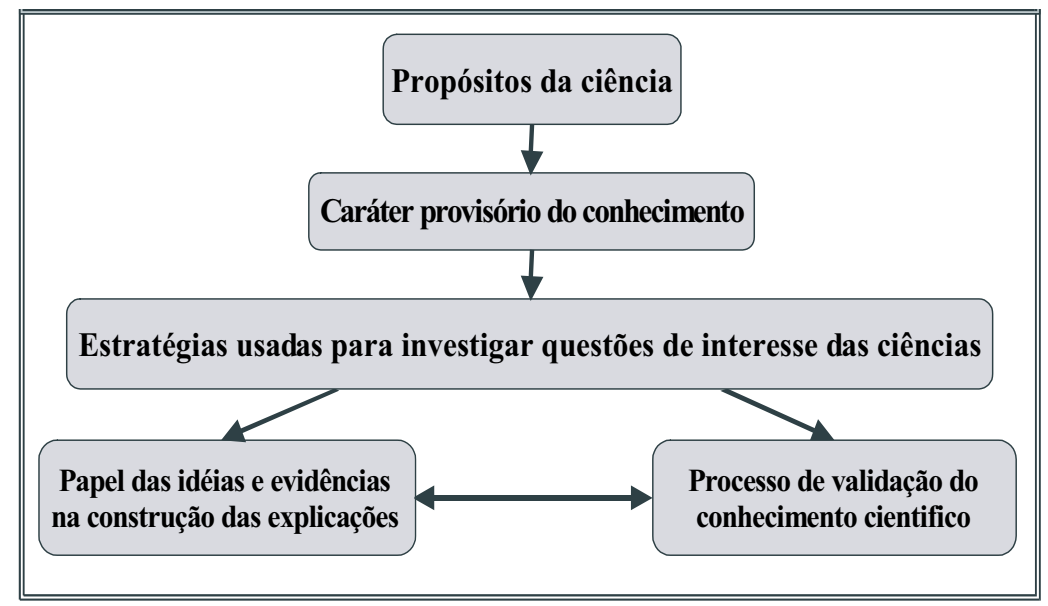

Diagrama 1-Aspectos da atividade cientifica contemplados nas atividades de ensino aprendizagem.

Nossa opção foi ensinar aspectos do conhecimento sobre a ciência no contexto de conteúdos usuais, adotando uma abordagem nova que tornasse explícitas essas idéias sobre ciência. Através das revisões bibliográficas que realizamos no início da pesquisa, definimos um conjunto de aspectos da atividade científica a serem contemplados em nossa pesquisa. Esses aspectos encontram-se representados no diagrama 1.

Um trabalho recente de Osborne et al. (2003) foi concebido, justamente, para identificar quais eram os aspectos da natureza das ciências sobre os quais

\footnotetext{
${ }^{2}$ Nunca é demais lembrar que o conhecimento sobre a ciência de que falamos aqui se distingue do conhecimento científico em si mesmo, que é o conhecimento sobre o mundo natural gerado no interior das ciências. Na verdade, o conhecimento sobre a ciência é um metaconhecimento e, nesse sentido, transcende as ciências naturais em direção à filosofia, à epistemologia, às ciências cognitivas e às ciências sociais.
} 
havia acordo na hora de se definir o que deveria ser ensinado, preferencialmente, na educação básica. $\mathrm{O}$ estudo utilizou a metodologia Delphi e contou com a participação de uma ampla comunidade de especialistas. Entre os participantes do estudo havia pesquisadores e educadores da área de ciências naturais, bem como intelectuais e cientistas envolvidos com a popularização das ciências.

Esses autores constataram um amplo consenso entre os especialistas em torno de um conjunto limitado de idéias mais gerais que devem ser contemplados na educação básica. Tal consenso destoa da grande tensão entre epistemólogos, historiadores e sociólogos das ciências que se esforçaram na tentativa de caracterizar as ciências. A esse respeito, Feyrabend (1979, p. 165) nos diz que a dificuldade de caracterizar as ciências liga-se, antes de tudo, à própria complexidade da atividade científica.

As escolhas que fizemos em nossa pesquisa estão em boa concordância com os resultados da pesquisa de Osborne e colegas (2003), embora apontem para aspectos que não foram contemplados, ou caracterizem de modo um pouco diferente as dimensões da natureza das ciências apresentadas no diagrama 1. Todavia, nada encontramos no referido trabalho, acerca dos critérios ou parâmetros para coordenar, na educação básica, a compreensão do conteúdo das idéias das ciências e dos processos de produção ou validação do conhecimento científico.

Um dos caminhos que decidimos trilhar na busca de definir esses critérios e as orientações didático-metodológicas a eles relacionadas foi o de destacar o papel da imaginação e da modelização na produção das ciências. Isso foi feito por meio de reflexões suscitadas pelos textos e atividades que compunham o material didático utilizado pelo professor da turma cujo trabalho nós acompanhamos em sala de aula.

Os dados apresentados neste artigo constituem uma pequena parte de um conjunto maior de evidências que nossa pesquisa produziu a favor do sucesso da experiência de ensino-aprendizagem no sentido de contribuir para que os estudantes compreendessem essa dimensão essencial da atividade científica. A idéia de que as ciências pressupõem imaginação e modelização se liga a outras dimensões igualmente importantes para a caracterização da natureza das ciências representadas no diagrama 2 . O espaço deste artigo não nos permite discutir todas essas conexões e a importância delas para a educação em ciências. Essa discussão mais ampla pode, no entanto, ser encontrada em Paula (2004). 


\section{Metodologia}

Durante três meses, filmamos as aulas de ciências de um professor que se interessou em participar da pesquisa e utilizar atividades de ensino-aprendizagem concebidas por um de nós, orientadas no sentido de promover reflexões sobre a natureza das ciências. Logo no início desse período, realizamos uma entrevista de avaliação diagnóstica destinada a identificar imagens das ciências e raciocínios epistemológicos dos estudantes em relação a aspectos da atividade científica apresentados no diagrama 1. Uma parte dos dados construídos nessa entrevista inicial foi discutida em publicações anteriores (PAULA; BORGES 2002, 2003; PAULA, 2004).

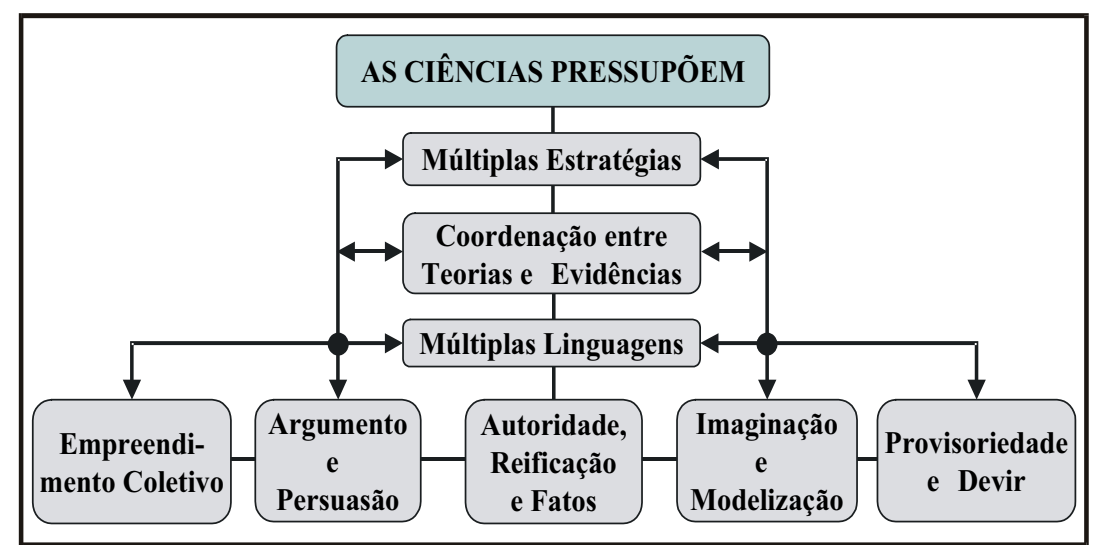

Diagrama 2- Dimensões indissociáveis e complementares da natureza das ciências.

Um ano e meio após ter terminado o período em que acompanhamos as aulas de ciências, quando os estudantes estavam prestes a concluir a última série do Ensino Fundamental, voltamos a entrevistá-los com o objetivo de avaliar possíveis avanços de seu conhecimento epistemológico. Tomamos como referência tanto as imagens e os raciocínios identificados na entrevista inicial, quanto as expectativas criadas pelo trabalho que havia sido feito em sala de aula. As quatro fases da entrevista final realizada com esse objetivo encontram-se apresentadas no quadro 1. Neste artigo, apenas alguns dos dados produzidos na análise da primeira fase são discutidos. 
Quadro 1 - Fases e objetivos da entrevista final conduzida com os estudantes.

\begin{tabular}{|l|l|}
\hline Fase 1 & O papel da imaginação na produção das ciências \\
\hline Fase 2 & A função dos experimentos nas ciências \\
\hline Fase 3 & A escolha e a disputa entre teorias \\
\hline Fase 4 & Contribuições da escola para a compreensão da atividade científica \\
\hline
\end{tabular}

Para conceber a entrevista final, um dos autores deste artigo releu atentamente as entrevistas iniciais e as categorias que haviam sido criadas para analisálas. Esse trabalho deu origem a registros de opiniões e raciocínios manifestados pelos estudantes, durante o período inicial de contato com a turma. Embora a comparação com a entrevista inicial fosse possível, o que prevaleceu mesmo na entrevista final foi o objetivo de avaliar a influência da ciência escolar em possíveis avanços da compreensão dos estudantes sobre a natureza da atividade e do conhecimento científicos. Para contemplar esse objetivo, produzimos instrumentos com textos e exemplos que já haviam sido apresentados aos estudantes nas atividades utilizadas nos três meses de trabalho em sala de aula que foram registrados em áudio e vídeo.

Tendo em vista o grande investimento feito naquele período, no sentido de tornar inteligível o modelo de partículas de Newton acerca da natureza e do comportamento da luz, decidimos utilizá-lo como elemento central dos instrumentos de pesquisa utilizados nas três primeiras fases da entrevista final. Para isso, também pesou a facilidade de relacionar tal modelo à idéia de que as ciências pressupõem Argumento e Persuasão, Imaginação e Modelização, ou a Coordenação entre Teorias e Evidências.

Produzimos uma série de questões para orientar a discussão de cada uma das quatro diferentes fases da entrevista, respondida em duplas pelos estudantes. Desse modo, a entrevista final pode ser classificada como semi-estruturada. Um cuidado tomado em todas as entrevistas foi o de dizer aos estudantes que o uso de exemplos extraídos do material didático utilizado em sala de aula no segundo trimestre letivo de 2001, praticamente um ano e meio antes da entrevista final, não deveria ser encarado como um "teste de memória".

Afirmamos, na ocasião, que nosso objetivo não era fazer uma avaliação da "retenção" das idéias contidas naquelas fichas. Ainda assim, aproveitamos a oportunidade para perguntar se eles se lembravam dos conteúdos expostos em cada 
ficha e se eles entendiam as idéias expostas nessas fichas. A grande maioria dos estudantes respondeu afirmativamente a essas duas questões, de modo que não houve problemas no uso das fichas como instrumentos de pesquisa.

Na primeira fase da entrevista final nossa intenção era conhecer as imagens dos estudantes sobre a natureza das explicações científicas. Mais exatamente, nós pretendíamos saber qual papel os estudantes atribuíam à imaginação e à criatividade no processo de construção das ciências, bem como avaliar se, ao assumir a presença de elementos oriundos da imaginação no conhecimento científico, os estudantes diminuiriam o status epistemológico atribuído a esse conhecimento. A entrevista começou com a leitura de uma ficha impressa a cores, em papel A4, reproduzida a seguir. Os estudantes foram orientados a ler e a analisar atentamente o modo como Isaac Newton (1642-1727) explicou a dispersão da luz branca e a formação do arco-íris (Fig. 1).

Antes de propor as questões concebidas para a discussão da ficha, dissemos a todos os estudantes que aquele exemplo de explicação não deveria ser entendido, necessariamente, como um "padrão" de explicação científica. Quando pedimos aos estudantes para avaliar a natureza daquela explicação, fizemos questão de dizer que eles poderiam considerar aquele exemplo, tanto como um padrão de explicação científica, quanto como um "caso à parte", ou uma "exceção que fugia à regra". Aproveitamos essa sugestão para perguntar aos estudantes se o uso que aquela explicação fazia de elementos extraídos da imaginação estava mais próximo de ser regra ou exceção nas ciências.

Há um aspecto delicado acerca dessa fase da entrevista que precisamos esclarecer. $\mathrm{O}$ interesse do pesquisador não era discutir e avaliar o conhecimento das duplas sobre o modelo de Newton para dispersão da luz. O modelo fora estudado no primeiro semestre do ano anterior, e esta é a razão porque decidimos usálo como base para a entrevista. Nosso interesse era discutir sobre o entendimento, ou não, dos estudantes quanto ao papel desempenhado pela imaginação na criação do modelo de dispersão da luz. Em vista disso, o entrevistador esteve todo o tempo preocupado em retomar o foco da entrevista, dando apoio para que os estudantes evoluíssem da análise do conteúdo do modelo para pensar em como ele foi produzido, ou reformular as falas dos estudantes para voltar à questão de interesse: a origem da explicação da dispersão da luz. A preocupação do entrevistador não era de sugerir respostas, mas de criar um ambiente de apoio para a reflexão dos estudantes sobre a origem do modelo de Newton, contrastando a possibilidade de que ele tivesse se baseado em observações ou, ao contrário, estivesse baseado em propriedades de partículas meramente imaginadas. 
Modelo de partículas de Newton e a origem das cores do arco-íris

As duas figuras seguintes reproduzem o raciocínio utilizado por Newton (1642-1727) para explicar a dispersão da luz branca nas cores do arco-íris. Analise com atenção essas figuras para tentar compreender como Newton explicou esse fenômeno.

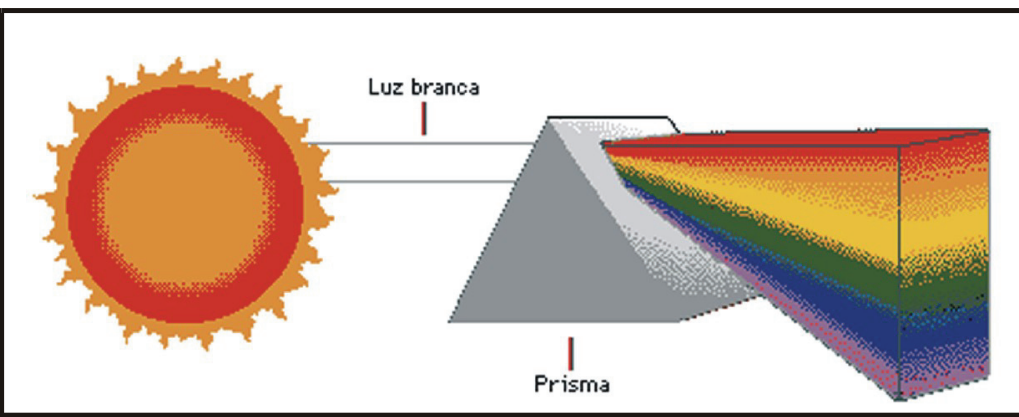

Realidade: Um feixe de luz branca, ao passar por um prisma, decompõe-se em feixes coloridos com as cores do arco-iris. A luz vermelha é a que sofre o menor desvio ao passar pelo prisma. A luz violeta é a que sofre o maior desvio.

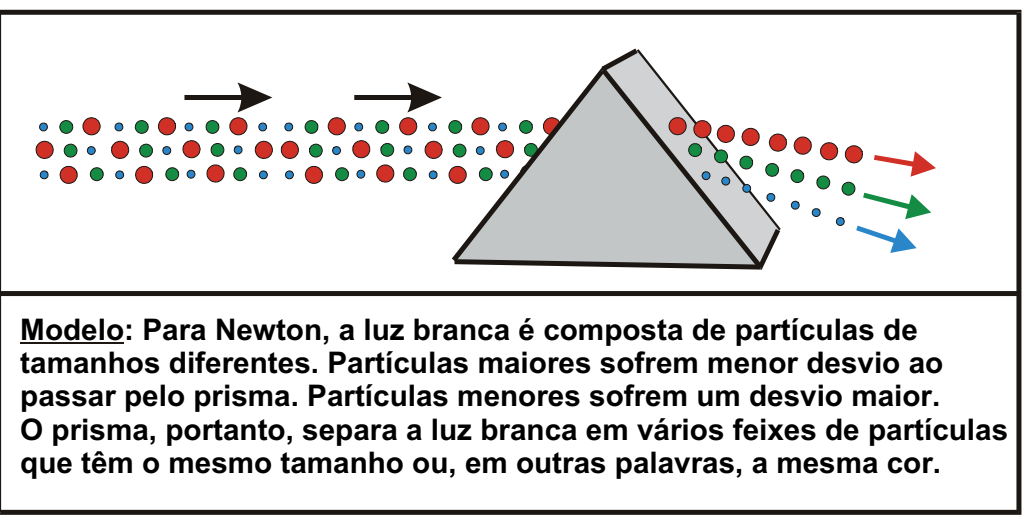

Fig. 1 - Um exemplo de explicação produzida no interior das ciências. 


\section{Resultados}

As respostas e opiniões dos estudantes na fase 1 da entrevista que analisamos neste artigo estão sumarizadas na tabela 1 por meio de quatro proposições. Essas proposições representam nossas tentativas de sintetizar a variedade de raciocínios apresentada pelos estudantes entrevistados. Na segunda coluna da tabela, indicamos o número de estudantes cujas falas têm alta identificação com o texto da proposição. Esse número é dado por uma fração cujo denominador é quatorze, número total de estudantes entrevistados. Na terceira e última coluna indicamos o número de estudantes cujos pontos de vista não podem ser completamente identifi-cados com o texto da proposição. Recorreremos a alguns trechos de transcrições para esclarecer que tipo de discrepância existiu entre as imagens ou raciocínios epistemológicos desses estudantes e as proposições sumarizadas na tabela 1.

Tabela 1- Respostas e opiniões dos estudantes na primeira fase da entrevista.

\begin{tabular}{l|c|c}
\hline \multicolumn{1}{c|}{ PROPOSIÇÃO } & $\begin{array}{c}\text { Concorda } \\
\text { plenamente }\end{array}$ & $\begin{array}{c}\text { Pensa } \\
\text { diferente }\end{array}$ \\
\hline $\begin{array}{l}\text { A explicação produzida por Newton para o fenômeno da } \\
\text { dispersão contém elementos extraídos da imaginação. }\end{array}$ & 12 & 2 \\
\hline $\begin{array}{l}\text { O uso da imaginação é inevitável quando se pretende } \\
\text { explicar o fenômeno da dispersão luminosa. }\end{array}$ & 12 & 2 \\
\hline $\begin{array}{l}\text { Para explicar é preciso ir além do que se pode efetiva- } \\
\text { mente observar. A produção de explicações nas ciências } \\
\text { pressupõe o uso da imaginação. Tal uso é regra e não } \\
\text { exceção. }\end{array}$ & 14 & 0 \\
\hline $\begin{array}{l}\text { Não se avalia a qualidade de uma explicação ou teoria } \\
\text { em função dela conter mais ou menos elementos extraí- } \\
\text { dos da imaginação. Existem outros critérios de avaliação. }\end{array}$ & 14 & 0 \\
\hline
\end{tabular}

Uma análise geral dos escores da tabela 1 permite reconhecer uma razoável sofisticação nas imagens dos quatorze estudantes entrevistados acerca da natureza das ciências. Afinal de contas, a partir de imagens ingênuas e raciocínios epistemológicos mais limitados não se costuma atribuir tamanha importância ao papel da imaginação na produção do conhecimento científico. 
Uma única dupla não expressou imediata e espontaneamente a idéia de que a explicação produzida por Newton para o fenômeno da dispersão contém elementos extraídos da imaginação. A dupla em questão é constituída pelas estudantes cujos nomes fictícios são Maria e Gabriela. Essas estudantes não chegaram a discordar da primeira proposição, mas apenas precisaram refletir melhor sobre ela. Vejamos um trecho do diálogo que sustenta essa análise do ponto de vista das estudantes sobre o papel da imaginação nas ciências. As enunciações estão numeradas para facilitar sua análise posterior. O pesquisador é um dos autores deste artigo.

E01 $\Rightarrow$ Pesquisador: ...Vocês estão dizendo que Newton observou com bastante cuidado a experiência. Aí ele conseguiu criar essas idéias aí, é isso mesmo?

E02 $\Rightarrow$ Gabriela: É, ué. Ele estudou, como é que fala... fez experiência... Não sei como, porque naquela época, né?... Fez do jeito dele. Aí ele fez a experiência e conseguiu, né?

$$
\begin{aligned}
& \text { E03 } \Rightarrow \text { Pesquisador: Conseguiu inventar essas idéias? } \\
& \text { E04 } \Rightarrow \text { Maria: É. }
\end{aligned}
$$

E05 $\Rightarrow$ Pesquisador: Bom... Essas particulas de luz fazem parte da explicação dele. Elas podem ser observadas? Dá para observar as bolinhas associadas às cores?

$$
\text { E06 } \Rightarrow \text { Maria: Não! }
$$

E07 $\Rightarrow$ Pesquisador: Minha dúvida é se isso vem de observação ou da imaginação, entedenderam?

E08 $\Rightarrow$ Maria: Ah... Entendi.

E09 $\Rightarrow$ Pesquisador: Se não dá para observar partículas de luz, e se a explicação está baseada nisso...

$E 10 \Rightarrow$ Maria: Isso é a imaginação dele!

E11 $\Rightarrow$ Pesquisador: A explicação está baseada nisso, cada cor tem um tipo de partícula. A explicação faz sentido?

E12 $\Rightarrow$ Gabriela: Faz. 
E15 $\Rightarrow$ Pesquisador: Bom, então tá. Vamos recapitular: primeiro vocês falaram, assim, que é mais observação.

E16 $\Rightarrow$ Maria: Ele imaginou essas partículas para quê? Para tornar a sua experiência mais fácil, para que todo mundo entenda.

E17 $\Rightarrow$ Pesquisador: Ah, legal. É um recurso para explicar.

E18 $\Rightarrow$ Gabriela: É um recurso da explicação dele.

E19 $\Rightarrow$ Pesquisador: Ah... Entendi. Você também acha isso Maria?

E20 $\Rightarrow$ Maria: Eu acho. Para tornar mais aceitável.

Nota-se que, mediante a argumentação do pesquisador, as estudantes admitem que a explicação newtoniana para a dispersão da luz branca contém elementos extraídos da imaginação. Esses elementos, por essa razão, são compreendidos como estando além da mera observação, jamais podendo ser derivados diretamente dela. As estudantes parecem não terem se dado conta disso logo no início da interação com o pesquisador e essa é a razão que nos levou a associar as estudantes com a coluna "pensa diferente", situada na tabela 1. Apesar disso, no final do trecho transcrito e na seqüência do diálogo que não foi transcrito, Maria e Gabriela legitimam o uso da imaginação na produção das explicações desde um ponto de vista didático e retórico. Elas, aparentemente, caracterizam a imaginação como um recurso de argumentação e persuasão e não, propriamente, como um recurso heurístico ou uma parte intrínseca do raciocínio do cientista tomado isoladamente.

Nós mesmos não acreditamos que a distinção entre as dimensões retórica e heurística seja mais do que um recurso de análise da atividade científica. Essa é uma das conseqüências que se pode derivar de nosso argumento a favor da indissociabilidade entre a dimensão "Argumento e Persuasão", "Coordenação entre teorias e Evidências", "Imaginação e Modelização" e as outras dimensões que atribuímos à natureza das ciências no diagrama 2 .

Confessamos, todavia, não saber exatamente a razão pela qual as estudantes Maria e Gabriela legitimam o uso da imaginação na atividade científica. Pela análise do trecho acima transcrito vê-se que as estudantes reconhecem a legitimidade do uso da imaginação na explicação sobre a dispersão da luz proposta por Newton. Isso acontece quando elas afirmam que ele (Newton) tinha "necessidade de explicar" o processo de decomposição a outros sujeitos interessados em compreender o fenômeno. A partir de dados que produzimos em outras fases da entrevista e do período que estivemos a acompanhar as aulas de ciências, supomos que o ponto de vista dessas estudantes deriva de sua dificuldade em diferenciar a ciên- 
cia escolar e o empreendimento científico mais amplo. Desde esse ponto de vista, o cientista seria, basicamente, um professor que deve explicar aos outros como o mundo funciona.

Independentemente de ser classificada como uma "dificuldade" ou o resultado de um processo de indiferenciação, não há como negar que o ponto de vista apresentado por essas estudantes revela uma perspectiva bastante interessante. Ao "confundir" o papel do cientista, como produtor de conhecimentos, com o papel de um professor ou de um divulgador das ciências, as estudantes concebem os cientistas como sujeitos que não produzem conhecimento para si. Não se tratam, portanto, de pessoas meramente curiosas, maravilhadas com a possibilidade de descobrir os segredos da natureza. De acordo com essa perspectiva, a produção, a validação e a divulgação das ciências se confundem. O uso da imaginação parece permitir que todas essas funções, ainda indiferenciadas, sejam realizadas de modo eficaz.

Uma evidência a favor da idéia de que a indiferenciação que atribuímos às estudantes Maria e Gabriela traz consigo um germe de sofisticação das imagens sobre a natureza das ciências é o fato de que elas se utilizam desse mesmo raciocínio para defender as proposições 2 e 3 , sumarizadas na tabela 1 . Vejamos o trecho da entrevista que ilustra esse ponto.

E21 $\Rightarrow$ Maria: Ah, eu acho que no caso da ciência a gente mistura bastante a observação e a imaginação, porque hoje em dia as pessoas querem o quê, querem clareza, querem entender melhor. Por exemplo, se for só observação, se o cara colocar só a observação dele, talvez as pessoas não entendam.

E22 $\Rightarrow$ Gabriela: E a outra pessoa pode também perguntar: como que você observou isso?

E23 $\Rightarrow$ Pesquisador: E ele pode descrever: no quarto escuro, fiz um buraquinho na janela, deixei a luz do sol entrar, peguei um triângulo de vidro, fiz a luz passar. E ele está explicando como é que ele fez a experiência, né?

E24 $\Rightarrow$ Maria: Mas como é que ele vai provar para você?

E25 $\Rightarrow$ P: Provar o quê?

E26 $\Rightarrow$ Maria: A experiência dele, ué!

$E 27 \Rightarrow P:$ Mas a experiência não é só pegar a luz, fazer ela passar pelo triângulo de vidro, e desviar igual a gente fez no ano passado? 
E28 $\Rightarrow$ Maria: Mas eu acho, assim, mistura um pouco, sabe! Para quê? Para que as pessoas tenham mais clareza do que elas estão vendo.

$E 29 \Rightarrow P:$ É para entender o fenômeno?

E30 $\Rightarrow$ Gabriela: Isso.... É para tentar entender o porquê.

Constata-se, no trecho citado, que as estudantes Maria e Gabriela manifestam-se espontaneamente a favor das proposições 2 e 3 . Isso ocorreu depois delas terem aderido à idéia de que a explicação newtoniana contém elementos extraídos da imaginação e depois que elas desenvolveram o ponto de vista de que a imaginação é o principal recurso destinado a explicar para outras pessoas como ou porque um fenômeno ocorre de uma determinada forma.

As estudantes Maria e Gabriela não aderiram espontaneamente à primeira proposição, mas aderiram "entusiasticamente" às três proposições seguintes da tabela 1. Por sua vez, as estudantes Bruna e Zuleica, das quais passaremos a falar a partir de agora, aderiram espontaneamente à primeira proposição, mas não a generalizam e, por isso, não aderiram à segunda proposição. Desse modo, Bruna e Zuleica acabaram por constituir a única dupla de estudantes que não aderiu à segunda proposição da tabela 1. Apesar disso, e também em função de provocações e questões que o pesquisador introduziu durante a entrevista, a opinião das estudantes mudou, a ponto de permitir que elas aderissem à proposição de número 3, cujo conteúdo é extremamente similar ao da segunda proposição. Vejamos, então, um trecho ilustrativo dessa interação.

E31 $\Rightarrow$ Pesquisador: Essa presença de coisas da imaginação... Isso poderia ser evitado, poderia se evitar o uso da imaginação para explicar esse fenômeno? Vocês acham que tem jeito?

E32 $\Rightarrow$ Zuleica: Acho que ele teria que ter materiais suficientes para ele poder... Mas na época ele não tinha nada. Ele não tinha muitos recursos para poder saber...

E33 $\Rightarrow$ Pesquisador: Então, o uso da imaginação, no caso dele, é mais em função de uma falta de recursos?

E34 $\Rightarrow$ Zuleica: $E$

E35 $\Rightarrow$ Pesquisador: Eu disse que isso era só um exemplo de explicação. Será que as explicações na ciência, em geral, têm tanta imaginação assim? Isso é um caso mais raro? 
E36 $\Rightarrow$ Zuleica: Não.

E37 $\Rightarrow$ Pesquisador: Vocês disseram assim: o problema é a falta de recursos, não foi?

E38 $\Rightarrow$ Bruna e Zuleica (respondem juntas): $E$ !

E39 $\Rightarrow$ Pesquisador: E hoje em dia, as explicações das ciências têm menos imaginação?

E40 $\Rightarrow$ Zuleica: Têm menos que antes.

E41 $\Rightarrow$ Pesquisador: Menos que antes?

E42 $\Rightarrow$ Zuleica: $\dot{E}$.

E43 $\Rightarrow$ Pesquisador: Por exemplo, o negócio da constituição da matéria que vocês estudaram esse ano: átomos, moléculas. Ainda hoje em dia se pesquisa muito a constituição da matéria. Então, nesses assuntos, será que os recursos que a gente tem hoje nos ajudam a evitar o uso da imaginação, ou ainda tem muita imaginação, por exemplo, na teoria atômica?

E44 $\Rightarrow$ Zuleica: Tem o uso da imaginação também.

E45 $\Rightarrow$ Bruna: É, porque olha só, vamos pensar: existe, igual a gente estuda, igual o professor falou. A gente não pode provar, mas tudo mostra para a gente que é assim. Então, é a melhor explicação que a gente encontrou até hoje.

E46 $\Rightarrow$ Pesquisador: Ou seja, quando ele fala assim, ele está querendo dizer que parte da explicação envolve a imaginação?

E47 $\Rightarrow$ Bruna e Zuleica (respondem juntas afirmativamente): Hum, hum!

$\mathrm{Na}$ enunciação E43, o pesquisador faz uma intervenção que o coloca em uma posição ambígua. Nela se confundem o papel do entrevistador, que deseja identificar as imagens e raciocínios dos estudantes, com o papel do professor, que vê a interação verbal com os estudantes como uma oportunidade para promover avanços em suas imagens de ciências, determinando, assim, o quanto elas são dinâmicas, fluidas ou contextuais. A ambigüidade a que nos referimos traça uma linha muito tênue entre dois tipos diferentes de intervenção: $1^{\circ}$ - uma intervenção que procura colocar as imagens de ciências dos estudantes "em movimento"; $2^{\circ}$ uma outra que simplesmente "força os estudantes" a apresentar pontos de vista que "agradam ao entrevistador". 
Recair nesse segundo tipo de intervenção seria comprometer a validade dos dados que nossa pesquisa procurava construir. Evitá-la, por outro lado, é mais difícil do que parece, à primeira vista. Sinais muito sutis, captados na fala do pesquisador através de variações no tom de voz e nas expressões faciais, podem dar pistas aos estudantes sobre o que "deve ser dito", no sentido de "cooperar com a pesquisa". Por sorte, temos três indícios de que conseguimos, em E43, produzir o primeiro tipo de intervenção mencionado anteriormente. Temos, portanto, três razões para acreditar que os conteúdos das enunciações de E44 a E47 indicam uma reavaliação legítima e autêntica das estudantes acerca do papel da imaginação nas ciências.

Em primeiro lugar, o entrevistador procurou manter o mesmo tom de voz ao fazer intervenções para propor idéias que se aproximavam ou se afastavam das suas próprias imagens das ciências ou daquilo que consideramos mais próximo ou distante de um perfil epistemológico sofisticado. Essa é uma habilidade que ele não adquiriu na prática como entrevistador, até porque nunca desempenhou essa função de forma sistemática. Trata-se, isso sim, de um cuidado que ele aprendeu durante muitos anos nos quais tentou se tornar um professor que busca dialogar com os estudantes. Essa busca objetiva criar e gerenciar ambientes nos quais os estudantes formulam suas próprias idéias e aprendem a desenvolvê-las e a argumentar a favor delas, ao invés de apenas serem confrontados com os pontos de vista da ciência oficial, com toda a sua autoridade silenciadora, seus fatos e sua força retórica.

Em segundo lugar, julgamos que todos os estudantes com os quais trabalhamos eram suficientemente assertivos para não acatar sem questionamento sugestões por demais sutis que viessem a serem captadas nos gestos e na entonação de voz do pesquisador. Em terceiro e último lugar, acreditamos que a fala da estudante Bruna, em E45, exibe a consciência de que existe uma outra voz a considerar na tarefa de reavaliar a posição inicial que elas apresentaram acerca do papel da imaginação na produção das ciências. Trata-se, nesse caso, da voz de seu professor de ciências, que é introduzida no diálogo para justificar a idéia de que o uso da imaginação é legítimo e, por vezes, até necessário. De acordo com Bruna, o professor de ciências teria afirmado que, em situações onde "a gente não pode provar", resta a alternativa de acreditar na teoria ou explicação mais coerente com as evidências disponíveis, pois "tudo mostra para a gente que é assim".

O mais importante nesse tipo de caracterização das ciências, atribuída pelas estudantes ao seu professor de ciências, é a idéia de que teorias ou explicações produzidas mediante o uso da imaginação podem ser alvo de critérios razoavel- 
mente racionais na hora de serem avaliadas como as melhores, num determinado momento do processo de evolução do conhecimento científico. Nas palavras das próprias estudantes, trata-se da "melhor explicação que a gente encontrou até hoje". Esse ponto de vista associa duas das oito dimensões que nós atribuímos à natureza das ciências no diagrama II: Imaginação e Modelização + Provisoriedade e Devir.

Parece que a confiança na palavra do professor de ciências e a atenção ao modo como ele caracterizou o processo de produção do conhecimento científico em sala de aula foi capaz de nutrir e fazer avançar o entendimento das estudantes Bruna e Zuleica durante o processo de interação com o pesquisador. Evidências semelhantes sobre a influência do trabalho feito em sala de aula foram obtidas nas entrevistas com todos os outros quatorze estudantes que compunham a turma. $\mathrm{O}$ número de estudantes total na turma de oitava série era igual a vinte. Todavia, apenas 14 desses vinte estudantes haviam sido entrevistados no ano letivo anterior, na época em que realizamos a entrevista inicial de avaliação diagnóstica. Essa é a razão pela qual a tabela 1 apresenta um número total de apenas quatorze estudantes entrevistados.

As idéias apresentadas pelas estudantes Bruna e Zuleica para justificar sua adesão à quarta proposição da tabela 1 reforçam essa nossa interpretação. Vejamos, então, o trecho no qual esse "reforço" parece acontecer.

E48 $\Rightarrow$ Pesquisador: Agora, a pergunta é: ao usar a imaginação para produzir uma explicação, como Newton fez, ou como no caso do modelo atômico que vocês estudaram, o uso da imaginação torna a explicação mais frágil, pouco confiável, ou não é esse o critério para a gente decidir se a explicação é boa ou é ruim?

E49 $\Rightarrow$ Zuleica: Professor... Olha só... Eu acho que não é assim não, porque o modo de estudar as partículas para todo mundo hoje é esse, não é?! Por mais que todo mundo não tenha visto, o que a gente mais acredita é nisso. Eu acho que não é isso não. Acho que não é o melhor critério.

E50 $\Rightarrow$ Pesquisador: O fato de ter elementos da imaginação, não é critério para julgar que a coisa seja ruim, que a coisa seja fraca?

E51 $\Rightarrow$ Zuleica: É, não é não.

E52 $\Rightarrow$ Pesquisador: E qual seria o critério então? No caso da teoria das partículas, você falou: "A gente acredita". E por que, então, a gente acredita, já que está tudo baseado na imaginação? 
E53 $\Rightarrow$ Zuleica: Então, professor, é pelo tanto de experiência que a gente faz, se a gente usar isso, a gente sempre vai conseguir... Como é que eu vou falar... Arranjar uma explicação para isso.

E54 $\Rightarrow$ Pesquisador: A idéia parece boa em muitas situações?

E55 $\Rightarrow$ Zuleica: Isso. É isso mesmo.

E56 $\Rightarrow$ Pesquisador: Muda a experiência, e aquela idéia parece boa de novo?

E57 $\Rightarrow$ Zuleica: $\dot{E}$

E58 $\Rightarrow$ Pesquisador: É imaginação, mas parece boa. É assim?

E59 $\Rightarrow$ Zuleica: $\dot{E}$

E60 $\Rightarrow$ Pesquisador: Faz sentido!

E61 $\Rightarrow$ Bruna e Zuleica: (risos...)

O professor de ciências discutiu o modelo cinético-molecular da matéria, no início do ano de 2002. Isso ocorreu, portanto, cerca de 8 meses antes da entrevista analisada neste artigo ter sido realizada e 08 meses após o período em que acompanhamos e filmamos o uso, em sala de aula, de uma unidade temática sobre Luz e Visão, especialmente concebida para suscitar reflexões sobre a natureza das ciências. A semelhança entre a abordagem que o professor parece ter usado no tratamento do modelo cinético-molecular e aquela que foi utilizada no desenvolvimento do tema Luz e Visão pode ser resumida em uma idéia: nos dois casos o professor estruturou o processo de ensino-aprendizagem das ciências naturais centrando-o na análise de evidências, ou melhor, na coordenação entre teorias e evidências.

\section{Considerações finais}

A adesão das estudantes Bruna e Zuleica à quarta proposição da tabela 1 modifica uma linha de raciocínio identificada no primeiro trecho transcrito da entrevista com essas estudantes, visto que de E31 a E47, elas caracterizam o uso da imaginação como decorrente da falta de acesso a outros recursos.

As imagens das ciências das estudantes Maria e Gabriela mostraram-se bastante dinâmicas e capazes de evoluir rapidamente a partir do momento em que o pesquisador as convenceu de que a explicação newtoniana estava estruturada em 
torno de elementos imaginários. O mesmo pode ser dito acerca das estudantes Bruna e Zuleica e vários outros estudantes entrevistados. Em seu conjunto, as entrevistas nos levaram à conclusão de que um processo assistido ou compartilhado de reflexão, sustentado por vivências, conhecimentos e reflexões anteriores, pode nutrir e sustentar processos de sofisticação de imagens de ciência e raciocínio epistemológico em curtos intervalos de tempo. A perspectiva de ensinoaprendizagem sobre as ciências que se depreende desse raciocínio encontra-se ilustrada no diagrama 3 a seguir.

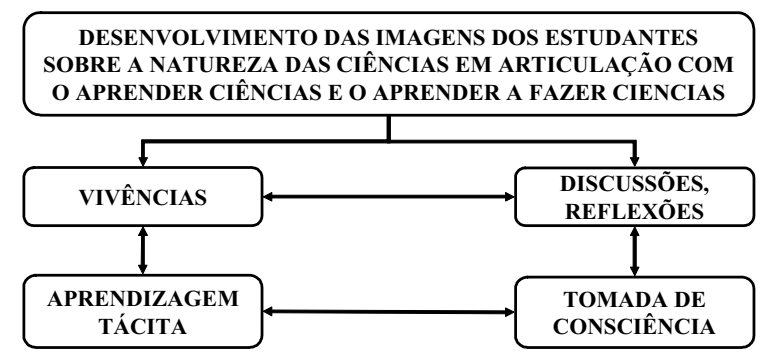

Diagrama 3

No trecho que vai de E31 a E42, e em outros trechos de entrevistas não transcritas neste artigo, encontramos elementos que nos permitem conjecturar que, em algumas situações, estes estudantes podem exibir pontos de vista sobre as ciências que, em alguma medida, podem ser associadas com algumas teses do positivismo lógico. Nesse e em outros trechos, encontramos uma nítida tentativa de restringir o papel da imaginação na produção do conhecimento científico. A associação das idéias iniciais de Bruna e Zuleica com o positivismo lógico deve ser vista com bastante cuidado. De modo algum estamos querendo equiparar noções epistemológicas pouco estruturadas e sistematizadas com um corpo de conhecimentos tão sofisticado como é o positivismo lógico. Ainda assim, a aproximação pode ser realizada se nos lembrarmos que o positivismo lógico considera a imaginação como uma etapa necessária, mas intermediária, no fazer das ciências. Desde o ponto de vista dessa epistemologia, pode-se vincular, por um lado, a imaginação com o processo de produção e, por outro lado, a observação, verificação ou confirmação, com o processo de validação do conhecimento sobre o mundo natural.

A variabilidade e a coexistência de diferentes conjuntos de concepções epistemológicas dos estudantes e de suas concepções sobre vários tópicos da ciência escolar podem ser interpretadas como bandas de um perfil epistemológico. A 
aposta em relação à existência desse tipo de perfil baseia-se na hipótese de que os estudantes não dispõem de epistemologias bem constituídas e coerentes (no caso tratado aqui). Desde essa perspectiva, o que percebemos como bandas de um perfil epistemológico pode ser também entendido como a manifestação de fragmentos de noções epistemológicas que ainda não foram objeto de reflexão sistemática. Tais fragmentos poderiam, por essa razão, serem superficialmente identificados com teses parciais de epistemologias conhecidas, tal como fizemos ao aproximar idéias das alunas Bruna e Zuleica com noções atribuídas ao positivismo lógico. .

Em nossa linha de pesquisa, a despeito da discussão que fizemos a partir da entrevista com as alunas Bruna e Zuleica, não nos interessamos em recortar extratos de idéias e raciocínios dos estudantes para forçar sua associação com ideologias das ciências historicamente constituídas. Preferimos acreditar no dinamismo e na falta de formalização e de sistematicidade das imagens dos estudantes sobre a natureza das ciências. Em nossa opinião, tais imagens e os raciocínios a elas associados fazem parte de "bandas" de um perfil epistemológico sobre o qual a escola deve atuar ao integrar o "saber ciências" com o "saber sobre as ciências" $\mathrm{e}$ o "saber fazer ciências".

Além disso, a região do perfil epistemológico de alguns estudantes, a partir da qual encontramos tentativas de restringir o uso da imaginação, não são de todo ruins, já que contêm germes de uma compreensão histórica do desenvolvimento das ciências e da estreita vinculação entre desenvolvimento científico e tecnológico. Esses germes podem ser explorados durante um processo de reflexão assistida ou compartilhada que promova a compreensão de que a imaginação é um recurso imprescindível à atividade científica, e que essa é uma das razões pelas quais o conhecimento científico é sempre provisório.

Ao contrário dos estudantes que iniciaram a entrevista impondo restrições ao papel da imaginação, os estudantes que o admitiram inequivocamente, desde o início, exibiram imagens de ciências e raciocínios epistemológicos mais sofisticados que apontaram claramente para a crença no caráter provisório do conhecimento científico.

Nos últimos anos, tem crescido entre os profissionais da educação em ciências, tanto professores, quanto pesquisadores, a convicção de que promover a compreensão dos estudantes sobre a natureza das ciências e da investigação científica é uma meta importante para um currículo de ciências voltado para a construção da cidadania.

Os dados apresentados neste artigo mostram que os estudantes situados em um ambiente que os apóie a realizar reflexões de caráter epistemológico foram 
capazes de aprender idéias importantes relacionadas com a natureza da ciência e de reconhecer que as ciências propõem explicações baseadas em entidades inobserváveis. Esse é um passo importante para que os estudantes possam aprender a apreciar as ciências, compreendendo suas relações com a arte, com a literatura e outras manifestações culturais, também baseadas no espírito criativo humano.

Ao retornar àquela turma, após um ano e meio, foi gratificante notar quão facilmente os estudantes rememoravam o que tinham aprendido e discutido na sétima série. Notamos também que seu professor de ciências havia continuado o uso de estratégias que apresentamos a ele no ano anterior. Assim, a classe por nós investigada beneficiou-se do entusiasmo do professor que compreendeu muito bem o projeto subjacente aos materiais que produzimos para criar situações de discussão e debates sobre aspectos sobre a natureza do conhecimento científico. É preciso mais esforço para tornar estas práticas mais acessíveis a outros professores do Ensino Fundamental e Médio. O sucesso da experiência da turma que acompanhamos, bem como os avanços teóricos estimulados pela avaliação que fizemos de sua aprendizagem, nos permite, hoje, articular um referencial teórico que pode e deve subsidiar a intervenção dos professores no desenvolvimento de novas práticas na educação básica em ciências.

\section{Referências Bibliográficas}

AAAS - American Association for the Advancement of Science - Project 2061: Science for all Americans. New York: Oxford University Press, 1989.

AStOlfi, J. P.; DEVElAy, M. A didática das ciências. 2. ed. Campinas: Ed. Papirus, 1989.

AKERSON, V. L.; ABD-EL-KHALICK, F.; LEDERMAN, N. G. Influence of a reflective explicit activity-based approach on elementary teachers' conceptions of nature of Science. Journal of Research in Science Teaching, v. 37, n. 4, p. 295 $317,2000$.

ABD-EL-KHALICK, F.; LEDERMAN, N. G. Improving science teachers' conceptions of the nature of science: a critical review of the literature. International Journal of Science Education, v. 22, p. 665-701, 2000.

BACHELARD, G. A filosofia do não - Filosofia do novo espírito científico. Trad. José J.M. Ramos. Lisboa: Editorial Presença, 1991. 
CHEVELLARD, Y. La transposición didática: del saber sabido al saber enseñado. Madrid: Aique Grupo Editor, 1991.

DUSCHL, R. A. Reestructuring science education: the importance of theories, and their development. New York: Teachers College Press, 1990.

FEYRABEND, P. K. Consolando o especialista. In: LAKATOS, I.; MUSGRAVE, A. (Orgs.). A Crítica e o Desenvolvimento do Conhecimento. São Paulo: Cultrix, Editora da Universidade de São Paulo, 1979. p. 109-243.

HODSON, D. Toward a philosophically more valid science curriculum. Science Education, v. 72, p. 151-183, 1988.

LEACH, J.; LEWS J. The role of student's epistemological knowledge in the process of conceptual change in Science. In: LIMON, M.; MASON, L. (Eds.). Reconsidering conceptual change: issues in theory and practice. Dordrecht: Kluwer Academic Publishers, 2002. p. 201-216.

LEACH, J.; RYDER, J. Designing and evaluating short teaching interventions about the epistemology of Science in high school classrooms. Wiley Periodicals, Inc. Sci Ed 87:831-848, 2003. Disponível em:

$<$ http://www.interscience.wiley.com>. Acesso em: 10 jun. 2005.

LEDERMAN, N. G. Students' and teachers' conceptions of the nature of Science: a review of research. Journal of Research in Science Teaching, v. 29, p. 331359, 1992.

LEMKE, J. Enseñar todos los lenguajes de la Ciencia: palabras, símbolos, imágenes y acciones. In: BENLLOCH, M. (Org.). La Educación en Ciencias: ideas para mejorar su práctica. Barcelona: Ediciones Piados Ibérica, 2002.

MILLAR, R. Towards a Science curriculum for public understanding. School Science Review, v. 77, p. 7-18, 1996.

MILLAR, R.; OSBORNE, J. Beyond 2000 - Science Education for the Future: The report of a seminar series funded by the Nuffield Foundation. London: King's College, School of Education, 1998.

MINISTÉRIO DA EDUCAÇÃO E CULTURA - MEC. Diretrizes curriculares nacionais para o ensino médio brasileiro. Brasília: MEC, 1998 
NATIONAL RESEARCH COUNCIL. National science education standards. Washington: National Academy Press. 1996.

OSBORNE, J. F.; COLlinS, S.; RATClifFE, M.; MILlAR, R.; DUSCHL, R. What "ideas-about-Science" should be taught in School Science? A Delphi Study of the Expert Community. Journal of Research in Science Teaching, v. 40, n. 7, p. 692-720, 2003.

PAULA, H. F. A ciência escolar como instrumento para a compreensão da atividade científica. 2004. 364 p. Tese (Doutorado) - Faculdade de Educação, UFMG, Belo Horizonte.

PAULA, H. F.; BORGES, A. T. Imagens de estudantes do Ensino Fundamental sobre os propósitos e as metas da ciência. In: VIANNA, D. M.; PEDUZZI, L. O. Q.; BORGES, O. N.; NARDI, R. (Orgs.). ENCONTRO DE PESQUISA EM ENSINO DE FÍSICA, VIII, 2002, Águas de Lindóia. Atas... p 1-12.

PAULA, H. F.; BORGES, A. T. Imagens dos estudantes sobre o uso de argumentos e evidências na construção de um fato científico. In: ENCONTRO INTERNACIONAL DE LINGUAGEM, CULTURA E COGNIÇÃO, II, 2003, Belo Horizonte. Campinas: Graf FE-Unicamp, 2003. p. 1-13.

RUBBA, P. A.; ANDERSON, H. O. Development of na instrument to assess secondary school students' understandings of the nature of Science. Science Education, v. 62, p. 449-458, 1978.

SONGER, N. B.; LINN, M. C. How do students' views of Science influence knowledge integration? Journal of Research in Science Teaching, v. 28, p. 761784, 1991. 